\title{
Effects of melatonin on ovarian reserve in cigarette smoking: an experimental study
}

Emre Kole ${ }^{1}$, Sebiha Ozdemir Ozkan¹, Ceyla Eraldemir², Furuzan Yildiz Akar ${ }^{3}$, Sema Kurnaz Ozbek ${ }^{4}$, Merve Cakir Kole ${ }^{1}$, Tugba Kum², Pelin Costur Filiz ${ }^{5}$

\author{
'Department of Gynecology and Obstetrics, Faculty of Medicine, Kocaeli University, \\ Kocaeli, Turkey \\ 2Department of Biochemistry, Faculty of Medicine, Kocaeli University, Kocaeli, Turkey \\ ${ }^{3}$ Department of Pharmacology, Faculty of Medicine, Kocaeli University, Kocaeli, Turkey \\ ${ }^{4}$ Department of Histology and Embryology, Faculty of Medicine, Kocaeli University, \\ Kocaeli, Turkey \\ IIVF Unit, Konak Hospital, Kocaeli, Turkey
}

Submitted: 2 July 2019

Accepted: 15 October 2019

Arch Med Sci 2020; 16 (6): 1376-1386

DOI: https://doi.org/10.5114/aoms.2019.89409

Copyright $\odot 2019$ Termedia \& Banach

\begin{abstract}
Introduction: The aim of the study was to investigate whether melatonin has a protective effect against diminished ovarian reserve induced by smoking. Material and methods: Seventy-two female Wistar-Albino rats were divided into 6 groups: group I (room air), group II (chronic cigarette smoking), group III (room air $+10 \mathrm{mg} / \mathrm{kg}$ subcutaneous melatonin), group IV (room air $+20 \mathrm{mg}$ / $\mathrm{kg}$ subcutaneous melatonin), group $\mathrm{V}$ (chronic cigarette smoking $+10 \mathrm{mg} / \mathrm{kg}$ subcutaneous melatonin), group VI (chronic cigarette smoking $+20 \mathrm{mg} / \mathrm{kg}$ subcutaneous melatonin). For 45 days, rats were exposed to cigarette smoke through a smoking machine, then subcutaneous melatonin was administered. Apoptotic index, immunohistochemical scoring, ovarian follicle counting, ovarian tissue and serum malondialdehyde (MDA), superoxide dismutase (SOD), glutathione peroxidase (GPX), and catalase (CAT) analyses were carried out. Results: All of the primordial, primary, secondary and mature follicle numbers were found to be significantly lowered in study groups. Increased HSCORE with anti-caspase-3 staining and a high follicular apoptotic index were demonstrated in the smoking group. Serum and ovarian tissue levels of MDA were found to be elevated with smoke exposure whereas lower MDA levels were determined in melatonin treated groups. Serum and tissue levels of SOD, GPx and CAT were shown to be reduced in the smoking group in comparison with melatonin treated and control groups. $20 \mathrm{mg} / \mathrm{kg}$ melatonin administration in the smoking group revealed significantly decreased HSCOREs and apoptotic indices.

Conclusions: Cigarette smoking has been definitely shown to be associated with impaired ovarian reserve with respect to significantly diminished numbers of primordial, primary, secondary and mature follicles. Dose-related treatment of melatonin in smokers may provide an evidently reduced apoptotic index and improved antioxidant activity in tissue.
\end{abstract}

Key words: melatonin, cigarette smoking, antioxidant, ovarian reserve.

\section{Introduction}

Cigarette smoke contains approximately 4700 chemical compounds, some of which are toxic, mutagenic and carcinogenic. Smoking is known

\author{
Corresponding author: \\ Emre Kole \\ Department \\ of Gynecology \\ and Obstetrics \\ Faculty of Medicine \\ Kocaeli University \\ 41380 Kocaeli, Turkey \\ Phone: +905309221337 \\ E-mail: \\ emre.kole.41@gmail.com
}


to have negative effects on human health. So far, it has been shown to lead to lung cancer, chronic bronchitis, and coronary heart diseases, while its adverse effects on reproductive issues appear to be less known [1]. However, smoking leads to sudden infant death syndrome, premature births, decreased fertility in women, early menopause and diminished ovarian reserve [2]. Although the prevalence of smoking has decreased globally, the number of smokers remained constant from 2007 to 2015 (1.1 billion in number) [3]. It has been reported that the prevalence of cigarette smoking, especially in women of reproductive age, is increasing worldwide, and one third of women in this age group are smokers [4].

Females are born with a fixed number of ovarian follicles in their ovaries, and this certain number of ovarian follicles, in which the development of the primordial follicles is arrested in meiosis stage I, are gathered together as primary, secondary, antral follicles in order to ovulate in puberty [4]. This follicular growth process continues until follicular pool depletion and menopause. Depletion of ovarian reserve, secondary to genetic abnormalities, aggressive treatments (radiotherapy of cancer), ovarian surgery (for endometriosis), idiopathic and the negative effects of various environmental and lifestyle factors such as smoking may go through acceleration periods [5].

In smokers, follicular survival and cellular viability have been found to decrease in relation to increased pro-apoptotic markers, namely Bax, activated caspase 3, HSP 90ab1 and DNA fragmentation [6]. As a result of exposure of newborn ovaries to smoking, apoptosis was induced, and caspase 2-3 levels and DNA fragmentation were increased as well [7]. The chemicals that act on the aryl hydrocarbon receptors (AhR) in the cigarette have been shown to induce apoptotic pathways [8]. The depletion of the primordial follicle (PMF) pool due to apoptosis and subsequent follicular atresia appears to be one of the possible mechanisms of premature ovarian failure (POF) and infertility [9].

Reactive oxygen species (ROS) have been suggested to accumulate in the environment during the follicular growth in the long period of arrest of meiosis stage I. ROS-related mitochondrial DNA damage and mutations, telomere shortening and dysfunction are associated with reduced number and quality of oocytes [10]. ROS have been shown to be related to apoptotic cell death in ovarian follicles and granulosa cells and diminished antioxidant defense reactions [5]. The imbalance between the pro-oxidant and antioxidants in the follicular environment of the ovaries has been found to be associated with impaired folliculogenesis [11]. Present data pointed out that oxidative stress induces telomere dysfunction and ends with chromosomal instability and apoptosis [12].

Cigarettes contain many chemical-reactive molecules (such as carbon dioxide, hydrogen peroxide, nitrogen oxides) that contain reactive oxygen derivatives and free radicals. A significant increase in oxidative stress-induced apoptosis in rat ovarian tissues cultured with dimethylbenzanthracene (DMBA) (a chemical in cigarettes) was apparent whereas culture with glutathione demonstrated that cell death was prevented by antioxidants in natural conditions [4].

Melatonin ( $\mathrm{N}$-acetyl-5-methoxytryptamine) is a neurohormone produced in very different tissues such as the brain, eye, immune system and reproductive system $[13,14]$. Melatonin is known to be a powerful antioxidant molecule that acts through direct and indirect mechanisms [15]. Melatonin and its metabolites exert their direct activities through the process of cleaning ROS and reactive nitrogen species (RNS) [16, 17]. Melatonin is found to be produced in ovaries, cumulus cells, oocytes, follicular fluid and placenta in terms of reproductive function [14].

In this experimental study, we aimed to investigate the protective effects of melatonin, an antioxidant molecule, on oxidant-antioxidant balance and apoptotic pathways with respect to the negative impact of smoking on the ovarian reserve in cigarette smoke exposed rats.

\section{Material and methods}

\section{Animal maintenance and treatment}

The ethical approval was licenced by Kocaeli University Animal Research Ethics Committee (Project number 2015/37, Kocaeli, Turkey). The principles of the National Institutes of Health guide for the care and use of laboratory animals (NIH Publications No. 8023, revised 1978) were followed. All experiments were carried out between 9:00 a.m. and 12:00 p.m. under standard laboratory conditions $\left(22 \pm 2^{\circ} \mathrm{C}\right.$ room temperature, 12-h light/dark cycle with lights on at 7:00 a.m.). Tap water and food pellets were provided equally.

Seventy-two female Wistar-Albino rats were divided into 6 groups: group I (control group to be exposed to room air, $n=12$ ), group II (smoke exposure group, $n=12$ ), group III (room air $+10 \mathrm{mg} / \mathrm{kg} \mathrm{mel-}$ atonin group, $n=12$ ), group IV (room air $+20 \mathrm{mg}$ / kg melatonin group, $n=12$ ), group $\vee$ (smoke exposure group $+10 \mathrm{mg} / \mathrm{kg}$ melatonin group, $n=12$ ), group VI (smoke exposure group $+20 \mathrm{mg} / \mathrm{kg}$ melatonin group, $n=12$ ).

In groups exposed to smoking, applying the ISO3308:2012 (Routine analytical cigarette smoking machine - definitions and standard condi- 
tions) standard and using the exposure device designed in accordance with the standard and the FTC (Federal Trade Commission) method, 2 times a day for $1 \mathrm{~h}$ each, a total of 10 cigarettes per day were used. Each cigarette contained $9.7 \mathrm{mg}$ tar, $0.85 \mathrm{mg}$ nicotine and $11.7 \mathrm{mg}$ TPM (total particulate matter per cubic meter of air). A total of 45 days of exposure was ensured. Each smoking exposure cycle in the machine consisted of 1 cigarette puff per $2 \mathrm{~s}$ per cycle, followed by a 28 -second draw time, a total of $30 \mathrm{~s}$. The cigarette puff cycle was restarted after following the 30-second fresh air puff for each smoking cycle. In the groups where room air was planned to be given, room air was supplied with the same machine. Melatonin administration was performed as subcutaneous injection at doses of $10 \mathrm{mg} / \mathrm{kg}$ and $20 \mathrm{mg} / \mathrm{kg}, 2 \mathrm{~h}$ before the lights were turned off once a day. Melatonin injection was performed in the last 15 days of 45-day exposure [17-19].

\section{Tissue sample collection}

At the end of the experiment, anesthesia was performed on all of the rats by intraperitoneal injection of ketamine $(12.5 \mathrm{mg} / \mathrm{kg})$ and xylazine $(2.5 \mathrm{mg} / \mathrm{kg})$ and blood samples were acquired by cardiac puncture. Blood samples were immediately centrifuged and stored at $-40^{\circ} \mathrm{C}$ for consequent analysis. After the collection of blood samples, all the rats underwent oophorectomy by an appropriate surgical procedure. Left ovaries were fixed in $4 \%$ paraformaldehyde solution for light and fluorescein microscopic tissue processing. Right ovaries were quickly frozen at $-40^{\circ} \mathrm{C}$ for biochemical analysis.

\section{Light and fluorescein microscopic examinations}

The left ovarian tissues were dehydrated through ascending grades of ethanol and cleared in toluene, then embedded in paraffin. Serial sections of $5 \mu \mathrm{m}$ thickness were cut from each ovary and applied to poly-l-lysine coated microscope slides. Sections of the ovaries were stained with hematoxylin and eosin (H\&E) to determine follicle count and ovarian structure. Caspase- 3 and TUNEL-fluorescein methods were applied to the sections derived from the central portion of ovaries for immunohistochemical analysis.

\section{Histological analysis and follicle count}

$H \& E$ staining was applied on every $10^{\text {th }} \mathrm{sec}$ tion of the ovary so that each section was separated by a distance of approximately 50-60 $\mu \mathrm{m}$ from the next $10^{\text {th }}$ section to evaluate the ovarian structure and follicle count [20]. Ovarian follicles were counted and classified according to the fol- lowing follicle type: primordial follicle, primary follicle, secondary follicle, Graafian (mature) follicle [21]. All sections were evaluated with an optical microscope (Olympus CX41, Tokyo, Japan) and monitored with cellSens digital imaging software (Ver. 1.7.1) by an attached digital camera (Olympus DP26, Tokyo, Japan).

\section{Anti-caspase-3 immunohistochemical analysis}

Sections cut from the central portion of the ovary from each group were chosen to determine anti-caspase-3 immunoreactivity. 5- $\mu \mathrm{m}$-thick sections of the ovaries were de-paraffinized in toluene $(2 \times 10 \mathrm{~min})$, rehydrated through descending grades of ethanol $(100,96,90$, and $70 \%$; 5 min each) and rinsed twice for 2 min each with distilled water. The slides were placed for $5 \mathrm{~min}$ in an antigen retrieval solution, $0.01 \mathrm{M}$ citrate buffer $(\mathrm{pH}=6.0)$ in a microwave oven. The endogenous peroxidase was inhibited with $0.3 \% \mathrm{H}_{2} \mathrm{O}_{2}$ (Merck, Darmstadt, Germany) in methanol for $10 \mathrm{~min}$. Then, the slides were rinsed twice for 5 min each with phosphate-buffered saline (PBS, $\mathrm{pH}=7.6$ ) containing $0.3 \%$ Triton X-100 (PBS/Triton). The tissue sections were covered for $10 \mathrm{~min}$ by a protein block solution (Mouse and rabbit specific HRP/ DAB (ABC) detection IHC kit, Abcam, ab64264, UK) for blocking non-specific binding. Then the slides were rinsed once for 5 min in PBS/Triton. The tissue sections were covered with rabbit polyclonal anti-caspase-3 (ab4051; Abcam, UK) primary antibody (dilution factor $=1: 500$ ) and then incubated overnight at $4^{\circ} \mathrm{C}$ in a humidified chamber [22]. After rinsing the tissue sections with PBS/Triton $(4 \times 5 \mathrm{~min})$, biotinylated secondary antibody (Mouse and rabbit specific HRP/DAB (ABC) detection IHC kit, Abcam, ab64264, UK) was applied for $10 \mathrm{~min}$ at a room temperature. Then, slides were washed with PBS/Triton ( $4 \times 5 \mathrm{~min})$, streptavidin peroxidase solution was applied (Mouse and rabbit specific HRP/DAB (ABC) detection IHC kit, Abcam, ab64264, UK), and slides were incubated for $10 \mathrm{~min}$. Afterward, the tissue sections were rinsed with PBS/Triton (4 $\times 5 \mathrm{~min})$ and 3,3'-diamino benzidine (DAB) solution (Mouse and rabbit specific HRP/DAB (ABC) detection IHC kit, Abcam, ab64264, UK) was performed as a chromogen for 10 min. Slides were washed with PBS/Triton ( $4 \times 5 \mathrm{~min})$, adequate drops of Mayer's hematoxylin were added to cover the sections for counterstaining and they were incubated for $1 \mathrm{~min}$. The tissue sections were rinsed 7-8 times in tap water and mounted with mounting medium (ab64230; Abcam, UK) for light microscopic examination. All sections were evaluated with an optical microscope (Olympus CX41, Tokyo, Japan) and monitored with cellSens digital imaging software (Ver. 
1.7.1) by an attached digital camera (Olympus DP26, Tokyo, Japan). Anti-caspase-3 expression intensity of follicular cells was determined by a histological score (HSCORE) method. The intensity of anti-caspase-3 immunostaining was semiquantitatively evaluated by the following categories: 0 , no staining; 1+, weak staining; $2+$, moderate or intermediate staining; $3+$, intense or strong staining [23]. For each tissue section, the HSCORE value was created by summing the percentage of cells that were stained at each intensity category and multiplying that value by the weighted intensity of the staining, using the formula HSCORE $=\sum P i(i+1)$, where $i$ is the intensity score, and $P i$ is the percentage of labeled cells for each intensity within a range of $0-100 \%$.

\section{Terminal deoxynucleotidyl transferase- mediated dUTP nick end-labeling (TUNEL) assay}

In situ cell death detection was assessed by fluorescent labeling with the TUNEL method as described by the manufacturer (1168479591; Roche Applied Science, Indianapolis, IN, USA). In brief, 5 - $\mu$ m-thick sections of the ovaries were de-paraffinized in toluene $(2 \times 5 \mathrm{~min})$, rehydrated through descending grades of ethanol (100, 95,70 , and $30 \% ; 5 \mathrm{~min}$ each) and rinsed once for 3 min with distilled water. Excess water was removed on slides with a Kimwipe and tissue sections were surrounded by PAP pen. Then, sections were incubated for $15 \mathrm{~min}$ at $37^{\circ} \mathrm{C}$ in a solution of proteinase- $\mathrm{K}(\mathrm{pH}=7.4$, ab64220; Abcam, UK) diluted to $20 \mu \mathrm{g} / \mathrm{ml}$ in PBS for membrane permeabilization. Slides were rinsed twice for $3 \mathrm{~min}$ in PBS. Thereafter sections were incubated with the provided fluorescein-conjugated TUNEL reaction mixture in a humidified chamber for $60 \mathrm{~min}$ at $37^{\circ} \mathrm{C}$ in the dark. After incubation, slides were rinsed 3 times for $3 \mathrm{~min}$ in PBS. The sections were then mounted with mounting medium (ab64230; Abcam, UK). TUNEL-stained nuclei were examined under an inverted fluorescence microscope (Olympus IX53, Tokyo, Japan) (excitation wavelength: 515-565 nm).

\section{Tissue homogenization and serum preparation}

The ovarian tissues were weighed and homogenized in a 1/10 (weight /volume) ratio of phosphate-buffered saline (PBS; $0.1 \mathrm{M}, \mathrm{pH}$ 7.4) with a tissue homogenizer. The homogenates were centrifuged at $5000 \mathrm{rcf}$ for $5 \mathrm{~min}$ to separate the supernatants and stored in Eppendorf tubes at $-40^{\circ} \mathrm{C}$ until the time of analysis.

In order to obtain serum samples, blood samples taken into the tube without anticoagulant were centrifuged at $3500 \mathrm{rpm}$ for $10 \mathrm{~min}$ and the supernatants were stored at $-40 \mathrm{C}$ until analysis.

\section{Tissue protein determination}

Total protein determination was performed by a modified Lowry method. The tissue results of the parameters to be analyzed were determined by proportioning to the amount of tissue protein.

\section{Determination of tissue and serum MDA levels and CAT, GPX, SOD activities}

MDA, GPX, SOD and CAT measurements were conducted in tissue and serum by commercial enzyme-linked immunosorbent assay (ELISA) kits (EEL-0060, E-EL-R2456; Elabsience Biotechnology Co., Wuhan, China, 201-11-1705, 201-11-0169; Sunred Biotechnology Co., Shanghai, China, respectively) according to the manufacturer's instructions.

\section{Statistical analysis}

The statistical analysis was carried out using IBM SPSS 20.0 (SPSS Inc., Chicago, IL, USA). The Shapiro-Wilk test was used to assess the normality of the data. Comparisons of multiple samples were performed using one-way ANOVA with posthoc Tukey test for parametric variables with normal distributions and data were expressed as the mean \pm standard deviation (SD). The Kruskal-Wallis test was performed for nonparametric variables and data were reported using the median and interquartile range (IQR: $25-75^{\text {th }}$ percentile). Tests were performed within the $95 \%$ confidence interval and the significance level was determined to be based on a $p$-value $<0.05$.

\section{Results}

A total of 72 female Wistar-Albino rats were enrolled in the study. In group II and group III, 2 rats died (one in each group) and therefore were excluded from the study. With 12 rats in group I, IV, $\mathrm{V}, \mathrm{VI}$ each and 11 rats in group II and III each, the study was completed with 70 rats in total.

\section{Biochemical parameters \\ Biochemical data are shown in Table I.}

\section{Tissue and serum MDA levels}

Serum and tissue levels of MDA were significantly higher in the smoke exposure group in comparison with the control group ( $p<0.05)$. Significantly reduced MDA levels were detected in the treatment groups in comparison with the smoke exposure group $(p<0.05)$. No significant difference was determined between treatment groups $(p>0.05)$. 
Table I. Mean \pm SD of tissue and serum SOD, tissue and serum GPx, tissue and serum CAT, tissue and serum MDA levels in control, smoke exposure, room air + $10 \mathrm{mg}$ melatonin, room air + $20 \mathrm{mg}$ melatonin, smoke exposure + $10 \mathrm{mg}$ melatonin and smoke exposure $+20 \mathrm{mg}$ melatonin groups

\begin{tabular}{|c|c|c|c|c|c|c|}
\hline Parameter & Control & $\begin{array}{l}\text { Smoke } \\
\text { exposure }\end{array}$ & $\begin{array}{l}\text { Room air }+ \\
10 \text { mg mela- } \\
\text { tonin }\end{array}$ & $\begin{array}{l}\text { Room air }+ \\
20 \mathrm{mg} \text { mela- } \\
\text { tonin }\end{array}$ & $\begin{array}{l}\text { Smoke expo- } \\
\text { sure }+10 \mathrm{mg} \\
\text { melatonin }\end{array}$ & $\begin{array}{l}\text { Smoke expo- } \\
\text { sure }+20 \mathrm{mg} \\
\text { melatonin }\end{array}$ \\
\hline $\begin{array}{l}\text { Tissue SOD } \\
\text { [U/mg protein] }\end{array}$ & $14.97 \pm 3.08$ & $8.72 \pm 3.62^{\star}$ & $15.27 \pm 4.28^{+}$ & $17.37 \pm 5.65^{+}$ & $9.96 \pm 2.33^{*}$ & $14.15 \pm 4.36^{+}$ \\
\hline $\begin{array}{l}\text { Tissue GPx } \\
\text { [ng/mg protein] }\end{array}$ & $64.09 \pm 19.76$ & $32.42 \pm 13.08^{*}$ & $67.69 \pm 26.73^{+}$ & $101.52 \pm 29.55^{\star,+}$ & $44.60 \pm 21.58$ & $62.30 \pm 20.64^{+}$ \\
\hline $\begin{array}{l}\text { Tissue CAT } \\
\text { [U/mg protein] }\end{array}$ & $128.15 \pm 17.99$ & $85.84 \pm 17.14^{\star}$ & $144.91 \pm 19.19^{+}$ & $161.25 \pm 19.52^{*,+}$ & $102.69 \pm 27.20$ & $116.48 \pm 25.46^{+}$ \\
\hline $\begin{array}{l}\text { Tissue MDA } \\
\text { [ng/mg protein] }\end{array}$ & $90.79 \pm 31.79$ & $186.68 \pm 24.68^{*}$ & $86.79 \pm 27.13^{+}$ & $77.88 \pm 17.29^{+}$ & $132.55 \pm 35.20^{*_{,+}}$ & $108.90 \pm 20.76^{+}$ \\
\hline $\begin{array}{l}\text { Serum SOD } \\
{[\mathrm{U} / \mathrm{ml}]}\end{array}$ & $8.69 \pm 2.57$ & $4.03 \pm 0.91^{\star}$ & $10.71 \pm 1.82^{+}$ & $12.27 \pm 2.27^{\star,+}$ & $6.05 \pm 1.32^{*}$ & $7.52 \pm 1.96^{+}$ \\
\hline $\begin{array}{l}\text { Serum GPx } \\
{[\mathrm{ng} / \mathrm{ml}]}\end{array}$ & $17.25 \pm 5.24$ & $10.96 \pm 3.51^{*}$ & $16.57 \pm 2.97^{+}$ & $29.51 \pm 4.70^{\star,+}$ & $15.37 \pm 6.29^{+}$ & $18.56 \pm 5.87^{+}$ \\
\hline $\begin{array}{l}\text { Serum CAT } \\
{[\mathrm{U} / \mathrm{ml}]}\end{array}$ & $50.13 \pm 6.56$ & $31.45 \pm 8.76^{\star}$ & $59.23 \pm 15.96^{+}$ & $61.96 \pm 11.45^{+}$ & $42.33 \pm 13.18$ & $47.93 \pm 12.06^{+}$ \\
\hline $\begin{array}{l}\text { Serum MDA } \\
{[\mathrm{ng} / \mathrm{ml}]}\end{array}$ & $50.17 \pm 11.01$ & $84.88 \pm 18.92^{*}$ & $52.98 \pm 11.43^{+}$ & $42.28 \pm 8.95^{+}$ & $65.36 \pm 12.11^{\star_{+}}$ & $55.60 \pm 8.66^{+}$ \\
\hline
\end{tabular}

\section{Tissue and serum GPx, SOD, CAT activities}

Tissue and serum GPx, SOD, CAT activities were found to be significantly reduced in the smoke exposure group compared to the control group $(p<$ 0.05). Those parameters were shown to be significantly increased in all treatment groups, especially in smoke exposure $+20 \mathrm{mg} / \mathrm{kg}$ melatonin group $(p<0.05)$ in comparison with the smoke exposure group. No significant difference was determined between treatment groups $(p>0.05)$.

\section{Light microscopy}

H\&E staining demonstrated that ovarian tissues of the control group (group I) exhibited normal histological structure whereas cystic and degenerated follicles were observed in the smoking group (group II). Degenerated follicles were observed in the smoking $+10 \mathrm{mg} / \mathrm{kg}$ melatonin group (group III) while the histological structure of ovarian tissues was similar to the control group in the smoking $+20 \mathrm{mg} / \mathrm{kg}$ melatonin group (group IV). General ovarian structure, stroma and follicle images in all groups are presented in Figure 1. The follicle counts are shown in Table II.

Primordial follicles were found to be significantly different between the smoke exposure group and other groups. The number of primordial follicles was significantly reduced only in the smoke exposure group in comparison with the control group $(p=0.002)$. In the smoke exposure $+10 \mathrm{mg} /$ $\mathrm{kg}$ melatonin group, the number of primordial follicles was significantly lower than the control group ( $p=0.03$ ) whereas there was no statistically significant difference between control group and smoke exposure $+20 \mathrm{mg} / \mathrm{kg}$ melatonin group.

Primary follicle counts were significantly decreased in the smoke exposure group compared to the control group $(p=0.006)$. The number of primary follicles was found to be significantly increased in the smoke exposure $+20 \mathrm{mg} / \mathrm{kg}$ melatonin group in comparison with the smoke exposure group ( $p=$ 0.006). Primary follicles were significantly fewer in the smoke exposure $+10 \mathrm{mg} / \mathrm{kg}$ melatonin group than in the control group ( $p=0.047$ ).

Secondary follicle counts were significantly reduced in the smoke exposure group compared to the control group $(p=0.004)$. The number of secondary follicles was found to be significantly increased in the smoke exposure $+20 \mathrm{mg} / \mathrm{kg}$ melatonin group in comparison with the smoke exposure group $(p=0.020)$.

\section{Immunohistochemical analysis}

\section{Caspase-3 immunoreactivity}

HSCORE was calculated by immunohistochemical analysis with anti-caspase 3 and determining the staining intensity of ovarian cells in all groups.

The staining intensity of the cells determined by the immunohistochemical applications with anti-caspase 3 is shown in Figure 2 and HSCORE values of the groups are presented in Figure 2.

HSCORE was determined to be significantly increased only in the smoke exposure group (HSCORE = 21.3). HSCOREs of the smoke exposure $+10 \mathrm{mg} / \mathrm{kg}$ and smoke exposure $+20 \mathrm{mg} / \mathrm{kg}$ 

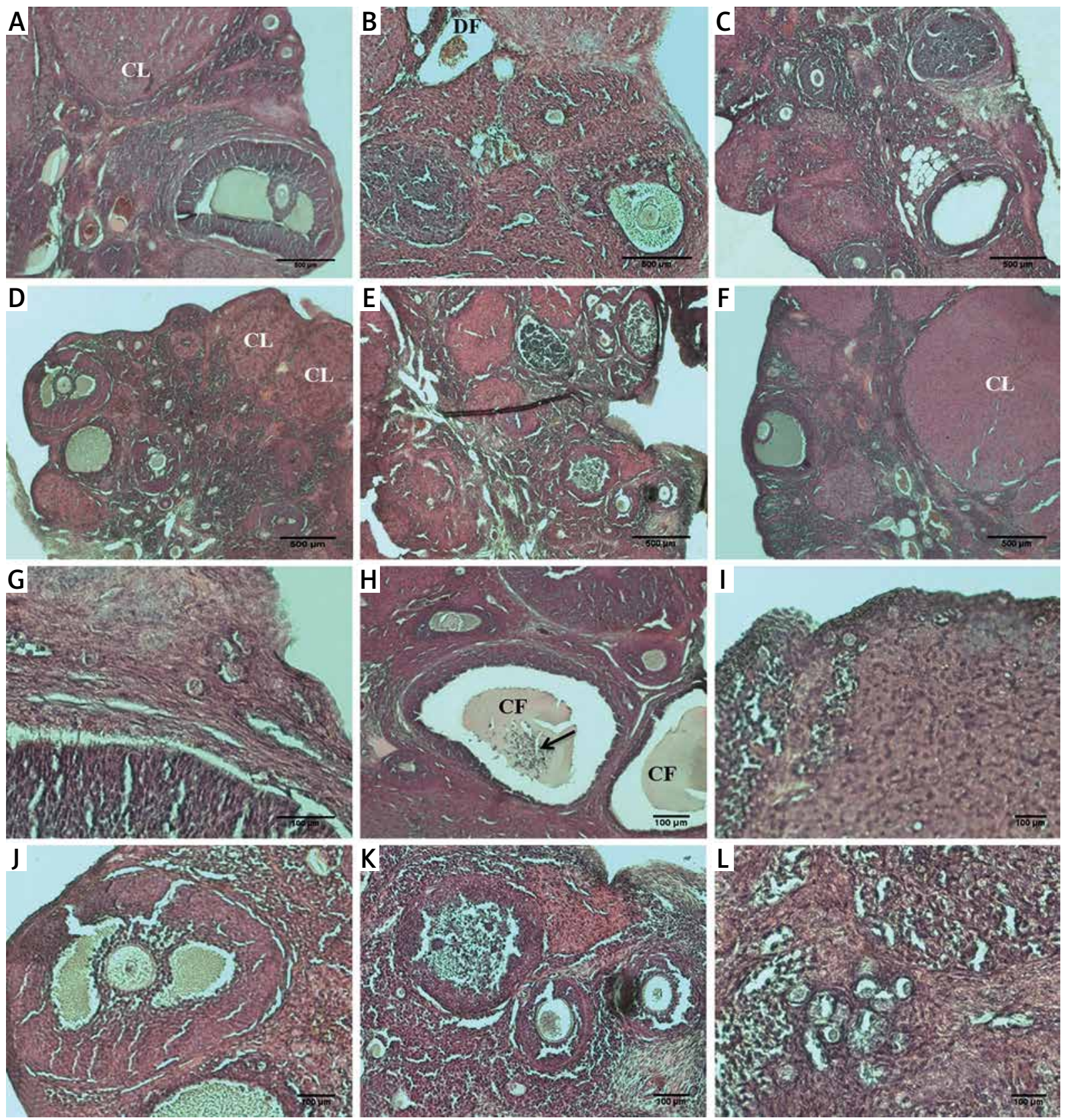

Figure 1. Histopathological alterations in ovarian sections of the control and the experimental groups. A - control, B - smoke exposure, C - room air + $10 \mathrm{mg} / \mathrm{kg}$ melatonin, D - room air + $20 \mathrm{mg} / \mathrm{kg}$ melatonin, E - smoke exposure + $10 \mathrm{mg} / \mathrm{kg}$ melatonin, $\mathbf{F}-$ smoke exposure $+20 \mathrm{mg} / \mathrm{kg}$ melatonin groups. $\mathrm{G}-\mathrm{L}-$ higher magnification of the follicles in these groups, respectively. A-F - magnification $4 \times, G-L-$ magnification 20x, H\&E)

$C F$-cystic follicle, DF-degenerated follicle, $C L$ - corpus luteum; arrow, apoptotic granulosa cells in antrum.

melatonin groups were found to be significantly reduced. Immunohistochemical analysis with anti-caspase 3 demonstrated an increased number of intense immunoreactive cells only in the smoke exposure group, whereas immunoreactive cells were found to be significantly reduced with decreased intensity in the smoke exposure $+20 \mathrm{mg} /$ $\mathrm{kg}$ melatonin group. The immunoreactive cells were found to be lowered in the smoke exposure $+10 \mathrm{mg} / \mathrm{kg}$ melatonin group in comparison to the smoke exposure group, although not as effectively as in the smoke exposure $+20 \mathrm{mg} / \mathrm{kg}$ melatonin group.

\section{TUNEL}

The images acquired by the TUNEL method that was applied to the ovarian sections of the control and experimental groups are shown in Figure 3. The apoptotic index ratios (AIR) calculated by the TUNEL method are shown in Figure 3.

According to immunofluorescence images acquired by the TUNEL method, apoptotic cells were 
Table II. Number of ovarian follicles in control, smoke exposure, room air $+10 \mathrm{mg} / \mathrm{kg}$ melatonin, room air $+20 \mathrm{mg} / \mathrm{kg}$ melatonin, smoke exposure $+10 \mathrm{mg} / \mathrm{kg}$ melatonin and smoke exposure $+20 \mathrm{mg} / \mathrm{kg}$ melatonin groups

\begin{tabular}{|lcccccc|}
\hline Parameter & Control & $\begin{array}{c}\text { Smoke } \\
\text { exposure }\end{array}$ & $\begin{array}{c}\text { Room air }+ \\
10 \text { mg mela- } \\
\text { tonin }\end{array}$ & $\begin{array}{c}\text { Room air }+ \\
20 \text { mg mela- } \\
\text { tonin }\end{array}$ & $\begin{array}{c}\text { Smoke expo- } \\
\text { sure }+10 \text { mg } \\
\text { melatonin }\end{array}$ & $\begin{array}{c}\text { Smoke expo- } \\
\text { sure }+20 \text { mg } \\
\text { melatonin }\end{array}$ \\
\hline $\begin{array}{l}\text { Primordial } \\
\text { follicle count }\end{array}$ & $11 \pm 3.59$ & $4 \pm 1.73^{*}$ & $9.18 \pm 2.14^{+}$ & $10.67 \pm 2.23^{+}$ & $7.25 \pm 1.82^{*,+}$ & $9.83 \pm 3.21^{+}$ \\
\hline $\begin{array}{l}\text { Primary follicle } \\
\text { count }\end{array}$ & $9.75 \pm 3.25$ & $4.09 \pm 1.3^{*}$ & $6.18 \pm 2.09^{*}$ & $8.17 \pm 2.62^{+}$ & $5.67 \pm 2.53^{*}$ & $7.08 \pm 1.88^{+}$ \\
\hline $\begin{array}{l}\text { Secondary } \\
\text { follicle count }\end{array}$ & $6 \pm 2.52$ & $2.55 \pm 1.37^{*}$ & $4.45 \pm 1.69$ & $5.33 \pm 1.87^{+}$ & $3.75 \pm 2.45$ & $4.92 \pm 1.16^{+}$ \\
\hline $\begin{array}{l}\text { Graafian } \\
\text { (mature) follicle } \\
\text { count }\end{array}$ & $2.5(2.0-3.75)$ & $1.0(0.0-2.0)^{*}$ & $1.0(0.0-3.0)^{*}$ & $2.0(1.0-3.0)$ & $1.5(0.0-2.0)^{*}$ & $1.5(1.0-2.75)$ \\
\hline
\end{tabular}

Values are expressed as mean $\pm S D$ for primordial, primary and secondary follicle counts and as median and interquartile range (IQR: $25-75^{\text {th }}$ percentile) for Graafian (mature) follicle count. *Versus control group, $p<0.05$; + versus smoke exposure group, $p<0.05$.

stained in large numbers and intensely in the smoke exposure group while apoptotic cells were found to be relatively small and decreased in intensity in the smoke exposure $+20 \mathrm{mg} / \mathrm{kg}$ melatonin group. Apoptotic cells were found to be relatively small and decreased in intensity in the smoke exposure $+10 \mathrm{mg} / \mathrm{kg}$ melatonin group as well, although not as effectively as in the smoke exposure $+20 \mathrm{mg} / \mathrm{kg}$ melatonin group.

\section{Discussion}

Approximately 4000 chemicals have been defined to be present in cigarette smoke (CS) and its negative impact on ovarian reserve has been demonstrated in various studies [8]. Gannon and his colleagues exposed rats to cigarette smoke twice a day for 5 days/8 weeks using a wholebody smoke exposure system [24]. Similarly, Tuttle et al. exposed rats to cigarette smoke twice a day for 7 days/8 weeks [18]. In both studies, it was concluded that ovarian volumes of the animals and the primary follicle numbers were significantly lower in the smoke exposure group. The mechanism of the effects of smoking is not precisely known although the negative effects of smoking on the ovarian reserve and follicle counts are inevitable according to literature data [1]. The literature data indicated that the primordial follicle has been particularly sensitive to toxic agents in primate models [25-27]. Our study indicated that the ovarian reserve is definitely impaired and the primordial follicle, primary follicle and secondary follicle numbers were significantly reduced by cigarette smoke.

In experimental studies evaluating the negative effects of smoking, two different models have been described in the literature: nose-only exposure (NOE) and whole-body smoking exposure [8, 9]. In the model where the rats are exposed to nose-only smoking, inhalation is achieved by special mechanisms and dermal exposure is less com- mon. Two separate studies of Sobinoff et al. which were designed in this way revealed that the primordial follicle activation was performed after dimethylbenzanthracene (DMBA) application [6, 7]. From this point of view, as in our study, rats are placed in a device leading to whole body smoking exposures involving all nasal, oral and dermal routes.

Smoking is one of the main sources of exogenous pro-oxidants and smoke contains a large amount of free oxygen radicals [19]. As a result of increasing ROS levels in blood after smoking, the balance between pro-oxidants and anti-oxidants shifts in favor of pro-oxidants, resulting in oxidative stress [28]. Literature data have shown that both enzymatic and nonenzymatic antioxidant levels are reduced in cigarette smokers [29]. In those studies, antioxidant capacity of follicular fluid was found to be low. Reactive oxygen species in the maturation stage and the final maturation process at the diplotene stage increase their developmental potential by ensuring the reactivation of meiotic oocytes. Like the free oxygen radicals, high levels of NO produced by oocytes or follicular somatic cells play an important role in oocyte maturation and physiology. High free oxygen radicals in the environment due to reduced $\mathrm{NO}$ levels can cause injury at the cellular level [30, 31]. Calcium ions $\left(\mathrm{Ca}^{2+}\right)$ accelerate the structural changes in the inner mitochondrial membrane and increase the free oxygen radical levels, leading to dysfunction of the mitochondrial respiratory chain.

Direct or indirect effects of melatonin on antioxidative enzymes brought into question its use as a powerful antioxidant. Its extremely low toxicity property, being able to be found in pure form, being relatively easy to obtain and not being expensive, have clearly expanded its use. The role of melatonin in reducing oxidative stress is stimulation of glutathione (GSH, a potent antioxidant) synthesis, reducing electron escape from the mito- 
A
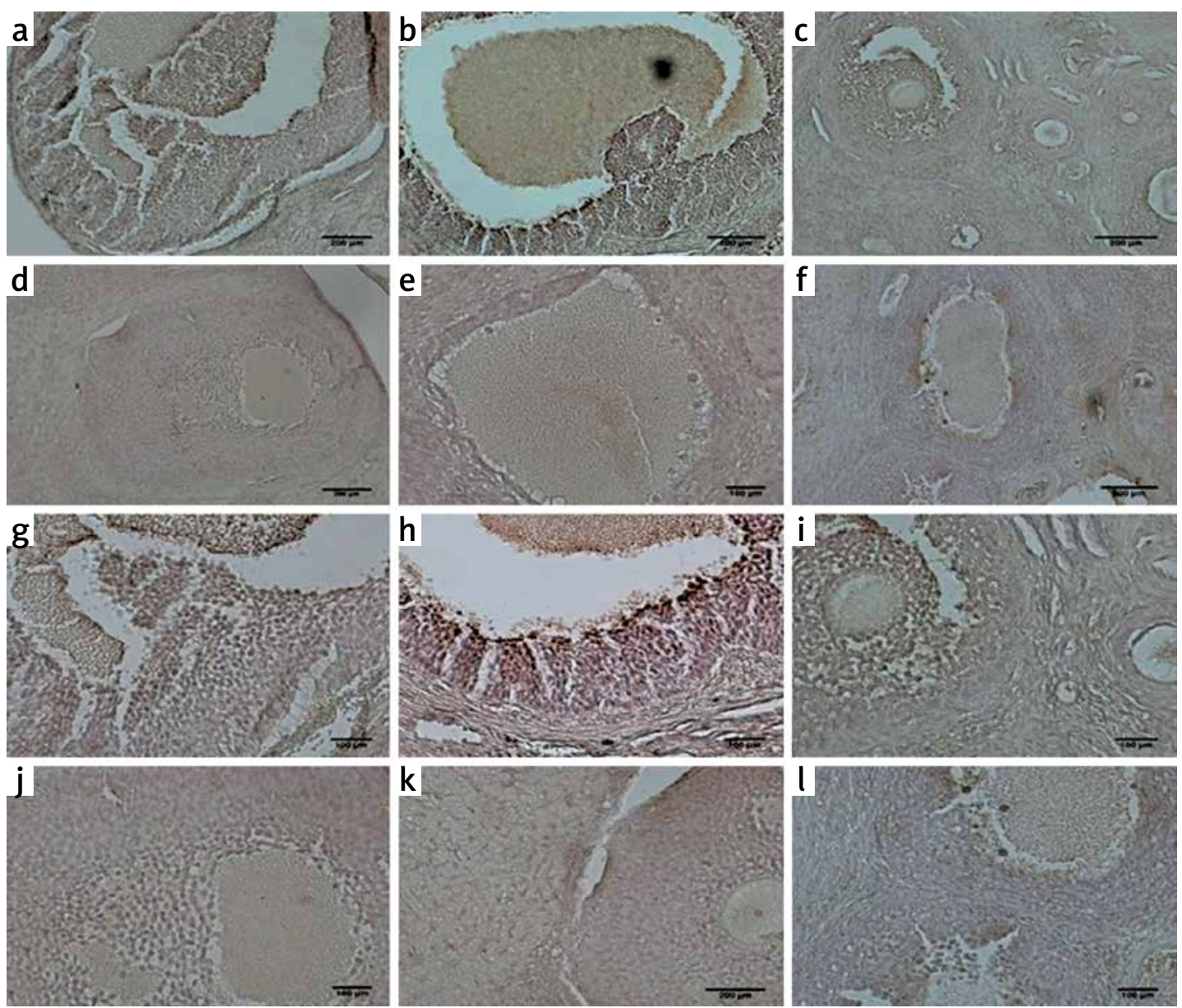

B

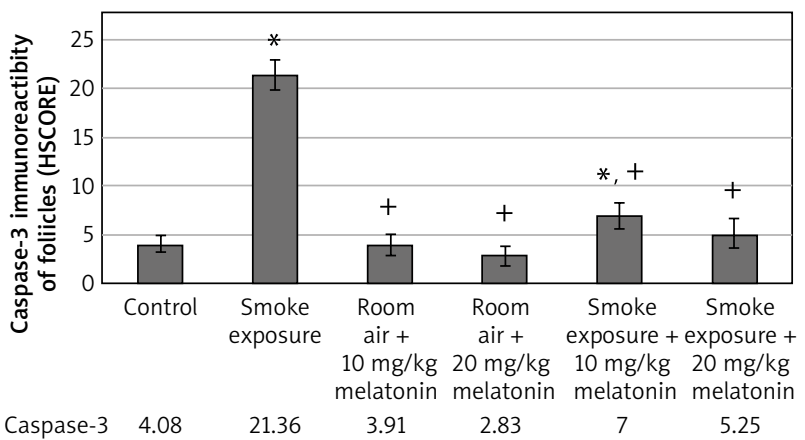

Values are expressed as mean $\pm S D$. *Versus control group, $p<0.05 ;+$ versus smoke exposure group, $p<0.05$.

Figure 2. A - Representative anti-caspase-3 immunoreactivity in ovarian sections of the control and experimental groups: $\mathbf{a}$ - control, $\mathbf{b}$ - smoke exposure, $\mathbf{c}$ - room air $+10 \mathrm{mg} / \mathrm{kg}$ melatonin, $\mathbf{d}$ - room air $+20 \mathrm{mg} / \mathrm{kg}$ melatonin, e -smoke exposure $+10 \mathrm{mg} / \mathrm{kg}$ melatonin, $\mathbf{f}$ - smoke exposure $+20 \mathrm{mg} / \mathrm{kg}$ melatonin groups, $\mathbf{g}-\mathbf{l}$ - higher magnification of the follicles in these groups, respectively (a-f - magnification 10x, g-l-magnification 20x). B - HSCORE of caspase-3 immunostaining in all groups

chondrial electron transport chain (reducing free radical formation), limitation of cytosine production of inflammatory processes (reduction of toxic reactant formation), and it has a synergistic effect with conventional antioxidants such as vitamin C, vitamin E or glutathione (GSH) [29]. In addition, melatonin inhibits $\mathrm{H}_{2} \mathrm{O}_{2}$-induced cell apoptosis by reducing the cytosolic free calcium concentration $\left(\left[\mathrm{Ca}^{2+}\right] \mathrm{c}\right)$. Melatonin, which is located directly in the follicular fluid (FF), can contribute to the development and reaching the fertilization stage of the preovulatory follicle.

In our study, melatonin given in room air significantly increased tissue levels of SOD, GPx and CAT. 
A
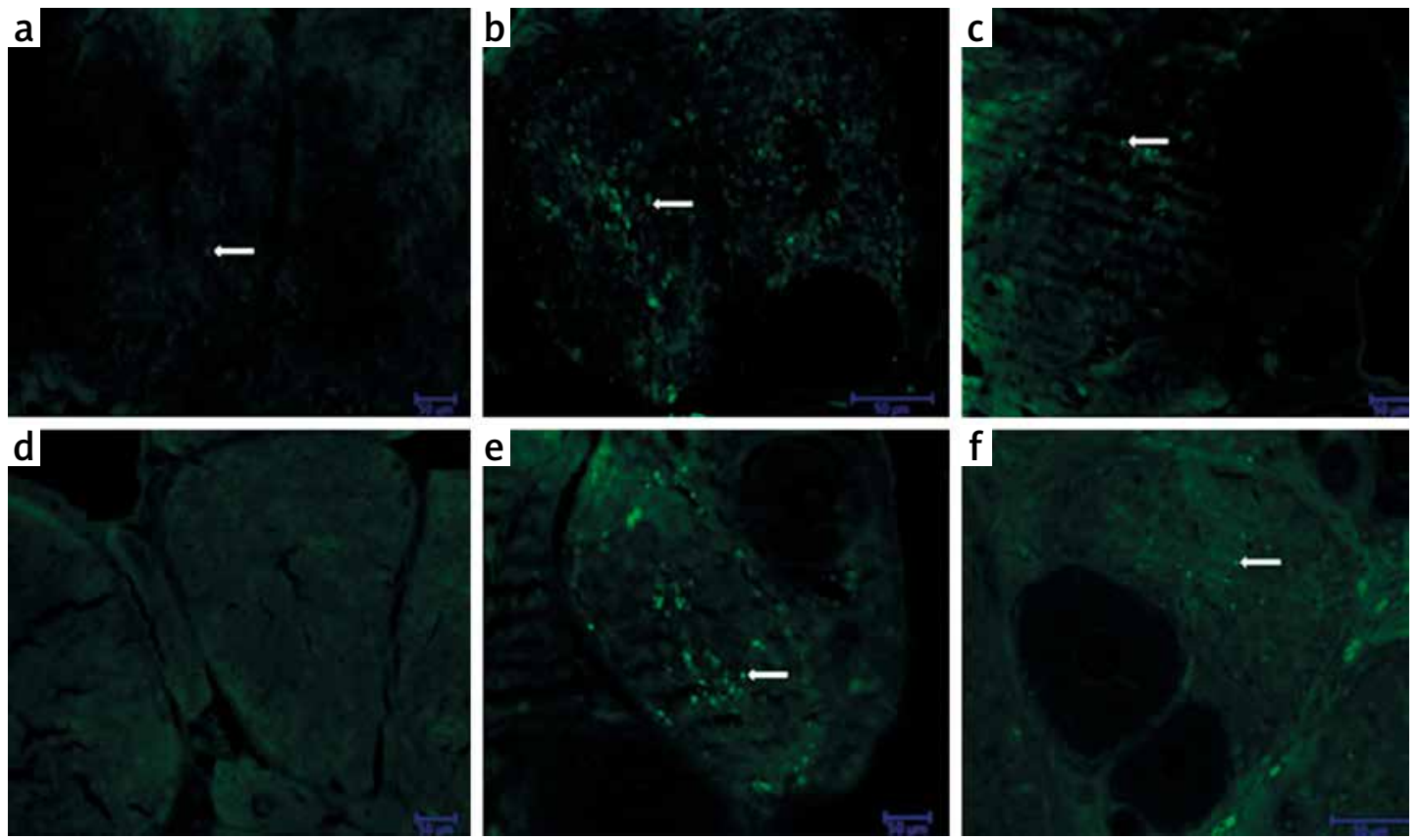

B

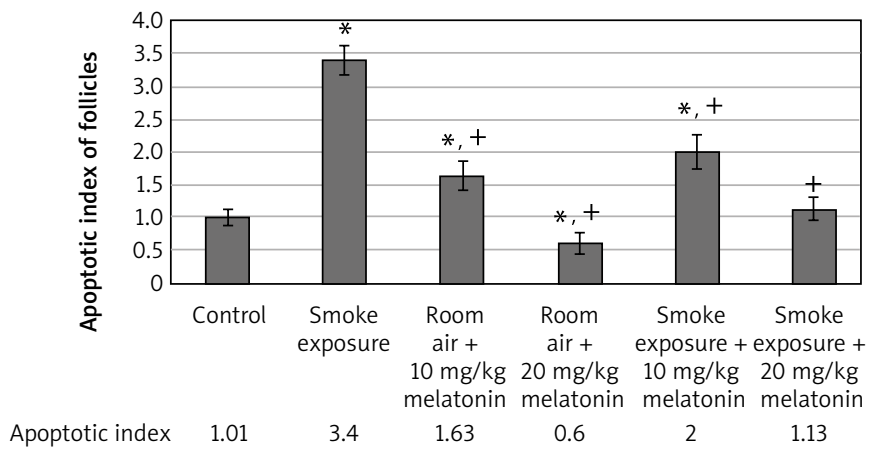

Values are expressed as mean $\pm S D$. *Versus control group, $p<0.05 ;+$ versus smoke exposure group, $p<0.05$

Figure 3. A - TUNEL-fluorescein analysis of ovarian follicles in control and experimental groups: a - control, b - smoke exposure, c - room air + $10 \mathrm{mg} / \mathrm{kg}$ melatonin, $\mathbf{d}$ - room air + $20 \mathrm{mg} / \mathrm{kg}$ melatonin, e - smoke exposure + $10 \mathrm{mg} / \mathrm{kg}$ melatonin, $\mathbf{f}-$ smoke exposure $+20 \mathrm{mg} / \mathrm{kg}$ melatonin groups. Apoptotic cells are indicated in green and shown with white arrows (a-f- magnification $10 \times)$. B - Apoptotic index of ovarian follicles in all groups

Tissue levels of CAT have been shown to be increased significantly in smoke exposure $+10 \mathrm{mg} / \mathrm{kg}$ and $20 \mathrm{mg} / \mathrm{kg}$. Melatonin administered in room air was concluded to significantly induce the antioxidant pathways. $20 \mathrm{mg} / \mathrm{kg}$ melatonin treatment in the smoke exposure group was demonstrated to increase the levels of SOD, GPx and CAT in ovarian tissue, suggesting that those enzymes act more effectively in ovarian tissue. Serum levels of SOD, GPX and CAT were found to be higher in the group receiving $20 \mathrm{mg} / \mathrm{kg}$ melatonin in comparison with the $10 \mathrm{mg} / \mathrm{kg}$ melatonin group, although it was not statistically significant, suggesting that the enzymes work more effectively in serum with $20 \mathrm{mg} / \mathrm{kg}$ melatonin administration as well. In our study, serum and tissue levels of antioxidant parameters (SOD, GPx, CAT) were found to be de- creased in the smoke exposure group whereas the same parameters were shown to be significantly increased in the smoke exposure + melatonin groups. Additionally, serum and tissue levels of MDA were significantly higher in the smoke exposure group in comparison with the control group whereas the same parameters of the smoke exposure $+20 \mathrm{mg} / \mathrm{kg}$ melatonin group were found to be similar to the control group, thus demonstrating that melatonin use at this dose significantly reduces the oxidant levels, achieving an antiapoptotic effect. In the smoke exposure $+20 \mathrm{mg} / \mathrm{kg}$ melatonin group, the number of follicles was found to be similar to the control group, thus indicating that melatonin exerts a protective effect for the ovarian follicles. Lastly, apoptotic indices detected by TUNEL and HSCORE results obtained 
by caspase-3 immunohistochemical analysis show similarities between smoke exposure $+20 \mathrm{mg} / \mathrm{kg}$ melatonin and control groups, suggesting positive effects of melatonin on apoptosis.

In our study, smoking was shown to increase apoptosis with respect to apoptotic indices and HSCOREs. Immunohistochemical analysis by anticaspase-3 and TUNEL immunofluorescence studies led us to conclude that there is a negative impact of smoking on ovarian reserve. Increased apoptosis detected in the ovarian stroma by TUNEL images of immunofluorescence staining confirmed this conclusion.

Duration might be one of the limitations of our study different from the literature. Tuttle et al. exposed rats to cigarette smoke for 8 weeks, which is different from our study protocol [18]. Our study is an animal study, which might be another disadvantage as physiology might not always reflect human physiology. One of the advantages of our study is that exposure intensity was more concentrated in a shorter time period, which might indicate dose-related effects. The way of exposure might be another advantage. Normally, the nasal exposure model investigates the local effects when compared to whole body exposure. Gannon and colleagues used the whole-body smoke exposure system, similar to our study [24]. In this way, it is possible to investigate the systemic effects of smoking beneath nasal effects.

The results of our study indicate a relation between smoke exposure and decline in ovarian reserve. Independent from way of exposure, either nasal or systemic, smoke exposure diminishes ovarian reserve. It is not clear whether this effect is reversible with antioxidant treatment. Different doses of melatonin might have a beneficial effect for the rejuvenation of ovarian reserve even though the exact mechanism is not known.

In conclusion, dose-related use of melatonin in smokers may be associated with a decreased apoptotic index and induced antioxidant activity in tissue in rat models. In our study, primordial follicle, primary follicle and secondary follicle numbers were significantly reduced because of cigarette smoking. That is why a decrease in follicle counts can reveal that ovarian reserve diminishes due to the negative effects of smoking, although melatonin which has antioxidant properties, should alter such adverse effects of smoking.

\section{Conflict of interest}

The authors declare no conflict of interest.

\section{References}

1. U.S. Department of Health and Human Services. The Health Consequences of Smoking - 50 Years of Prog- ress: A Report of the Surgeon General. Department of Health and Human Services, Centers for Disease Control and Prevention, National Center for Chronic Disease Prevention and Health Promotion, Office on Smoking and Health; Atlanta, GA, USA 2014; 1-36.

2. Benowitz NL, Brunetta PG. Smoking Hazards and Cessation. $5^{\text {th }}$ edn. Elsevier Inc., Amsterdam 2010; 257-62.

3. World Health Organization. Monitoring Tobacco Use and Prevention Policies. World Health Organization; Geneva, Switzerland 2017.

4. Camlin NJ, McLaughlin EA, Holt JE. Through the smoke: use of in vivo and in vitro cigarette smoking models to elucidate its effect on female fertility. Toxicol Appl Pharmacol 2014; 281: 266-75.

5. Soares SR, Melo MA. Cigarette smoking and reproductive function. Curr Opin Obstet Gynecol 2008; 20: 281-91.

6. Sadeu JC, Foster WG. Effect of in vitro exposure to benzo[a]pyrene, a component of cigarette smoke, on folliculogenesis, steroidogenesis and oocyte nuclear maturation. Reprod Toxicol 2011; 31: 402-8.

7. Sobinoff AP, Mahony M, Nixon B, Roman SD, McLaughlin EA. Understanding the Villain: DMBA-induced preantral ovotoxicity involves selective follicular destruction and primordial follicle activation through PI3K/Akt and mTOR signaling. Toxicol Sci 2011; 123: 563-75.

8. Coutts SM, Fulton N, Anderson RA. Environmental toxicant-induced germ cell apoptosis in the human fetal testis. Hum Reprod 2007; 22: 2912-8.

9. Vujovic S. Aetiology of premature ovarian failure. Menopause Int 2009; 15: 72-5.

10. Keefe DL, Liu L. Telomeres and reproductive aging. Reprod Fertil Dev 2009; 21: 10-4.

11. Ganesan S, Keating AF. Impact of 7,12-dimethylbenz[a] anthracene exposure on connexin gap junction proteins in cultured rat ovaries. Toxicol Appl Pharmacol 2014; 274: 209-14.

12. Igawa Y, Keating AF, Rajapaksa KS, Sipes IG, Hoyer PB. Evaluation of ovotoxicity induced by 7, 12-dimethylbenz[a]anthracene and its 3,4-diol metabolite utilizing a rat in vitro ovarian culture system. Toxicol Appl Pharmacol 2009; 234: 361-9.

13. Adriaens I, Jacquet P, Cortvrindt R, Janssen K, Smitz J. Melatonin has dose-dependent effects on folliculogenesis, oocyte maturation capacity and steroidogenesis. Toxicology 2006; 228: 333-43.

14. Reiter RJ, Tan DX, Korkmaz A, Rosales-Corral SA. Melatonin and stable circadian rhythms optimize maternal, placental and fetal physiology. Hum Reprod Update 2014; 20: 293-307.

15. Cruz MH, Leal CL, Cruz JF, Tan DX, Reiter RJ. Essential actions of melatonin in protecting the ovary from oxidative damage. Theriogenology 2014; 82: 925-32.

16. El-Sokkary GH, Khidr BM, Younes HA. Role of melatonin in reducing hypoxia-induced oxidative stress and morphological changes in the liver of male mice. Eur J Pharmacol 2006; 540: 107-14.

17. El-Sokkary GH, Cuzzocrea S, Reiter RJ. Effect of chronic nicotine administration on the rat lung and liver: beneficial role of melatonin. Toxicology 2007; 239: 60-7.

18. Tuttle AM, Stämpfli M, Foster WG. Cigarette smoke causes follicle loss in mice ovaries at concentrations representative of human exposure. Hum Reprod 2009; 24: 1452-9.

19. Valavanidis A, Vlachogianni T, Fiotakis K. Tobacco smoke: involvement of reactive oxygen species and stable free radicals in mechanisms of oxidative damage, carcino- 
genesis and synergistic effects with other respirable particles. Int J Environ Res Publ Health 2009; 6: 445-62.

20. Dorostghoal M, Mahabadi MK, Adham S. Effects of maternal caffeine consumption on ovarian follicle development in wistar rats offsping. J Reprod Infertil 2011; 12: 15-22.

21. Atilgan R, Kuloglu T, Boztosun A, et al. Investigation of the effects of unilateral total salpingectomy on ovarian proliferating cell nuclear antigen and follicular reserve: experimental study. Eur J Obstet Gynecol Reprod Biol 2015; 188: 56-60.

22. Kuyucu Y, Çelik LS, Kendirlinan Ö, Tap Ö, Mete UÖ. Investigation of the uterine structural changes in the experimental model with polycystic ovary syndrome and effects of vitamin D treatment: an ultrastructural and immunohistochemical study. Reproductive Biol 2018; 18: 53-59.

23. Rencber SF, Ozbek SK, Eraldemir C, et al. Effect of resveratrol and metformin on ovarian reserve and ultrastructure in PCOS: an experimental study. J Ovarian Res 2018; 11: 55.

24. Gannon AM, Stämpfli MR, Foster WG. Cigarette smoke exposure leads to follicle loss via an alternative ovarian cell death pathway in a mouse model. Toxicol Sci 2012; 125: 274-84.

25. Sobinoff AP, Pye V, Nixon B, Roman SD, McLaughlin EA. Adding insult to injury: effects of xenobiotic-induced preantral ovotoxicity on ovarian development and oocyte fusibility. Toxicol Sci 2010; 118: 653-66.

26. Sobinoff AP, Pye V, Nixon B, Roman SD, McLaughlin EA. Jumping the gun: smoking constituent $\mathrm{BaP}$ causes premature primordial follicle activation and impairs oocyte fusibility through oxidative stress. Toxicol Appl Pharmacol 2012; 260: 70-80.

27. Soleimani R, De Sutter P. In situ identification of follicles in ovarian cortex as a tool for quantifying follicle density, viability and developmental potential in strategies to preserve female fertility. Hum Reprod 2011; 26: 955-6.

28. Finkel T, Holbrook NJ. Oxidants, oxidative stress and the biology of ageing. Nature 2000; 408: 239-47.

29. Mohamed M, Sulaiman SA, Jaafar $H$, Sirajudeen $K N$. Antioxidant protective effect of honey in cigarette smoke-induced testicular damage in rats. Int J Mol Sci 2011; 12: 5508-21.

30. Cui MS, Wang XL, Tang DW, Zhang J, Liu Y, Zeng SM. Acetylation of H4K12 in porcine oocytes during in vitro aging: potential role of ooplasmic reactive oxygen species. Theriogenology 2011; 75: 638-46.

31. Meng J, Chen T, Zhao Y, et al. Experimental research study of the mechanism of anti-ulcer effects of virgin coconut oil on gastric ulcer-induced rat model. Arch Med Sci 2019; 15: 1329-35. 